\title{
Prevalence of Gastrointestinal Helminthes among Goats in and around Ranchi, Jharkhand, India
}

\author{
Anurag Jena ${ }^{1 *}$, Asit Ranjan Deb ${ }^{1}$, Lalita Kumari ${ }^{1}$, \\ Subhranshu Sekhar Biswal ${ }^{2}$ and S.K. Joshi ${ }^{3}$ \\ ${ }^{1}$ Department of Veterinary Parasitology, Ranchi Veterinary College, Kanke, Ranchi, \\ Jharkhand, India \\ ${ }^{2}$ Department of ARGO, CVSc. \& A.H., Bhubaneswar-751003, India \\ ${ }^{3}$ (Animal Science), KVK, Jharsuguda, OUAT, Bhubaneswar-751003, India
}

*Corresponding author

A B S T R A C T

Keywords

Gastro-intestinal helminths, Ranchi, Prevalence, Goats, Small ruminants, Helminth epidemiology

\section{Article Info}

Accepted: 26 December 2018 Available Online: 10 January 2018
In this present study, a total of 930 goats with symptoms of gastrointestinal infection were examined for the presence of gastrointestinal helminths of which $801(86.13 \%)$ were found to be positive. The different gastrointestinal helminths those were observed are Fasciola spp. and Paramphistomum spp. in trematodes; only Moniezia expansa and Moniezia benedeni in cestodes and among nematodes, Strongyloides spp., Trichostrongylus spp., Haemonchus spp., Trichuris spp., Oesophagostomum spp., Bunostomum spp., Ostertagia spp., Cooperia spp. and Marshallegia sp. Highly significant $(\mathrm{P}<0.01)$ relationships were recorded between season, age and sex wise variations with helminth prevalence. The present study provides the epidemiological pattern and risk factors associated with gastrointestinal helminth infection in goats in and around Ranchi, Jharkhand.

\section{Introduction}

In rural areas of our country, goat farming is one of the most important sources of livelihood of the farmers (Jithendran, 2000 and Bandyopadhyay et al., 2010). India ranks second in goat production with a population of 135.17 million goats and Jharkhand accounts to 6.58 million of goats (http://www.dahd. nic.in/documents/statistics/livestockcensus).
Reduction in productivity (body weight, milk and meat), increased mortality and morbidity leads heavy economic losses in goat production (Jithendran, 2000). This problem has been neglected time and again due to its chronic and insidious nature (Sanyal, 1998), although the losses are in millions of rupees (Shan and Chaudhry, 1995). It has always been a major impediment in small ruminant production and this problem is severe in 
tropical and sub-tropical climates due to favorable ecological factors available for transmission of helminth parasites (Gupta et al., 2013). Epidemiological pattern of gastrointestinal helminth parasites would shed some light for evolving strategic tactical control of these parasites (Jithendran, 2000). There is none to very little study in this sector in goats of Jharkhand. So, this study of prevalence of gastrointestinal helminths in goats in and around Ranchi has been designed to provide us with a clearer understanding of its epidemiological status.

\section{Materials and Methods}

No ethical committee approval was needed as this present study was conducted on fecal sample basis and fecal samples were collected from freshly void or directly from the animals' with prior permission of their owners.

Ranchi covers a geographical area of 175.12 $\mathrm{Km}^{2}$ with dense tropical forest and hilly topography. It's located in southern part of Chota Nagpur plateau nearer to Tropic of Cancer and lies at $23^{\circ} 22^{\prime} \mathrm{N} 85^{\circ} 20^{\prime}$. Ranchi has an average elevation of $651 \mathrm{~m}$ above sea level. An annual rainfall of $1430 \mathrm{~mm}$ is recorded at Ranchi with minimum and maximum ambient temperatures ranging from, 0 to $25^{\circ} \mathrm{C}$ in winter and 20 to $42^{\circ} \mathrm{C}$ in summer, respectively (https://www.weather-

forecast.com/locations/Ranchi).

The present study was conducted from November, 2011 to October, 2013. Animals showing gastrointestinal symptoms were taken in this study for fecal sample examination. The helminth ova were detected by Modified Sheather's Sugar floatation technique and Formal ether acetic acid technique was used for detecting eggs of trematodes (Sloss et al., 1984 and Zajac and Conboy, 2011). Fecal culture was conducted by modified Baermann's technique to identify the infective larval stages of helminths (Sloss et al., 1984 and Zajac and Conboy, 2011).

\section{Results and Discussion}

Out of 930 samples collected and examined from goats in and around Ranchi, 801 were recorded to be positive for gastrointestinal helminths (Table 1and Figure 1). Thus, the Overall prevalence was found to be $86.13 \%$. The different GI helminths those were observed are Fasciola spp. and Paramphistomum spp. in trematodes; only Moniezia expansa and Moniezia benedeni in cestodes and among nematodes, Strongyloides spp., Trichostrongylus spp., Haemonchus spp., Trichuris spp., Oesophagostomum spp., Bunostomum spp., Ostertagia spp., Cooperia spp. and Marshallegia sp. were recorded. The factors that could affect the prevalence are managemental practices, anthelmintics used, grazing habitat, economic strata of the farmer, farmer's educational background, climatic conditions, age and sex of the animals examined (Shan and Chaudhry, 1995; Sanyal, 1998 and Ahmed et al., 2017). This higher prevalence of gastrointestinal helminths is in accordance with other workers in India (Velusamy et al., 2015; Molla and Bandyopadhyay, 2016; Sanalkumar, 2017 and Jena et al., 2018) and abroad (Raza et al., 2014; Yeasmin et al., 2015, Ahmed et al., 2017 and Dabasa et al., 2017), in different climatic conditions. Nematodes were recorded to be of highest prevalence $(62.37 \%$ ) followed by trematodes $(56.02 \%)$ and cestodes (47.63\%) (Table 1 and Figure 1). Similar findings were reported by Gupta et al., in 2013; Poddar et al., Islam et al., Ahmed et al., Sanalkumar et al., and Sohail et al., in 2017 and in 2018 by Jena et al., The higher prevalence of gastrointestinal parasites in tropical, subtropical and also temperate climates could be attributed to their wide range of adaptability (Soulsby, 1966; Sanyal, 1998 and Poddar et al., 2017). 
Table.1 Prevalence of gastrointestinal helminthes of goats in and around Ranchi

\begin{tabular}{|c|c|c|c|c|c|c|c|c|c|}
\hline \multirow{2}{*}{ Group } & \multirow[b]{2}{*}{$\mathrm{N}$} & \multicolumn{2}{|c|}{ Overall G.I. helminths } & \multicolumn{2}{|c|}{ Trematodes } & \multicolumn{2}{|c|}{ Cestodes } & \multicolumn{2}{|c|}{ Nematodes } \\
\hline & & $\mathrm{P}$ & $\mathrm{PR} \%$ & $\mathrm{P}$ & PR\% & $\mathrm{P}$ & PR\% & $\mathrm{P}$ & PR\% \\
\hline & 930 & 801 & 86.13 & 521 & 56.02 & 443 & 47.63 & 580 & 62.37 \\
\hline \multicolumn{10}{|l|}{ Season } \\
\hline Rainy & 310 & 294 & 94.84 & 235 & 75.81 & 223 & 71.94 & 261 & 84.19 \\
\hline Winter & 310 & 269 & 86.77 & 169 & 54.52 & 119 & 38.39 & 206 & 66.45 \\
\hline Summer & 310 & 238 & 76.77 & 117 & 37.74 & 101 & 32.58 & 113 & 36.45 \\
\hline \multicolumn{2}{|l|}{$\mathrm{X}^{2}$} & \multicolumn{2}{|c|}{$42.50 * *$} & \multicolumn{2}{|c|}{$91.58 * *$} & \multicolumn{2}{|c|}{$112.18 * *$} & \multicolumn{2}{|c|}{$153.83 * *$} \\
\hline \multicolumn{10}{|l|}{ Age } \\
\hline $\begin{array}{l}0-3 \\
\text { month }\end{array}$ & 241 & 229 & 95.02 & 171 & 70.95 & 146 & 60.58 & 192 & 79.67 \\
\hline $\begin{array}{l}4 \text { to } 9 \\
\text { month }\end{array}$ & 355 & 319 & 89.86 & 241 & 67.89 & 199 & 56.06 & 263 & 74.08 \\
\hline $\begin{array}{l}>9 \\
\text { month }\end{array}$ & 334 & 253 & 75.75 & 109 & 32.63 & 98 & 29.34 & 125 & 37.43 \\
\hline \multicolumn{2}{|l|}{$\mathrm{X}^{2}$} & \multicolumn{2}{|c|}{$50.21 * *$} & \multicolumn{2}{|c|}{$116.25^{* *}$} & \multicolumn{2}{|c|}{$71.10 * *$} & \multicolumn{2}{|c|}{$140.03 * *$} \\
\hline \multicolumn{10}{|l|}{ Sex } \\
\hline Male & 281 & 222 & 79.00 & 111 & 39.50 & 96 & 34.16 & 124 & 44.13 \\
\hline Female & 649 & 579 & 89.21 & 410 & 63.17 & 347 & 53.47 & 456 & 70.26 \\
\hline \multicolumn{2}{|l|}{$\mathbf{X}^{2}$} & \multicolumn{2}{|c|}{$17.11 * *$} & \multicolumn{2}{|c|}{$44.60 * *$} & \multicolumn{2}{|c|}{$29.29 * *$} & \multicolumn{2}{|c|}{$57.06^{* *}$} \\
\hline
\end{tabular}

N- Total no. of goat examined; P -Total no. of goat positive; PR\% - Prevalence rate (\%); $\mathrm{X}^{2}$ - Chi Square value; ** - Highly significant relationship

Fig.1 Overall Prevalence of GI helminths in goats in and around Ranchi

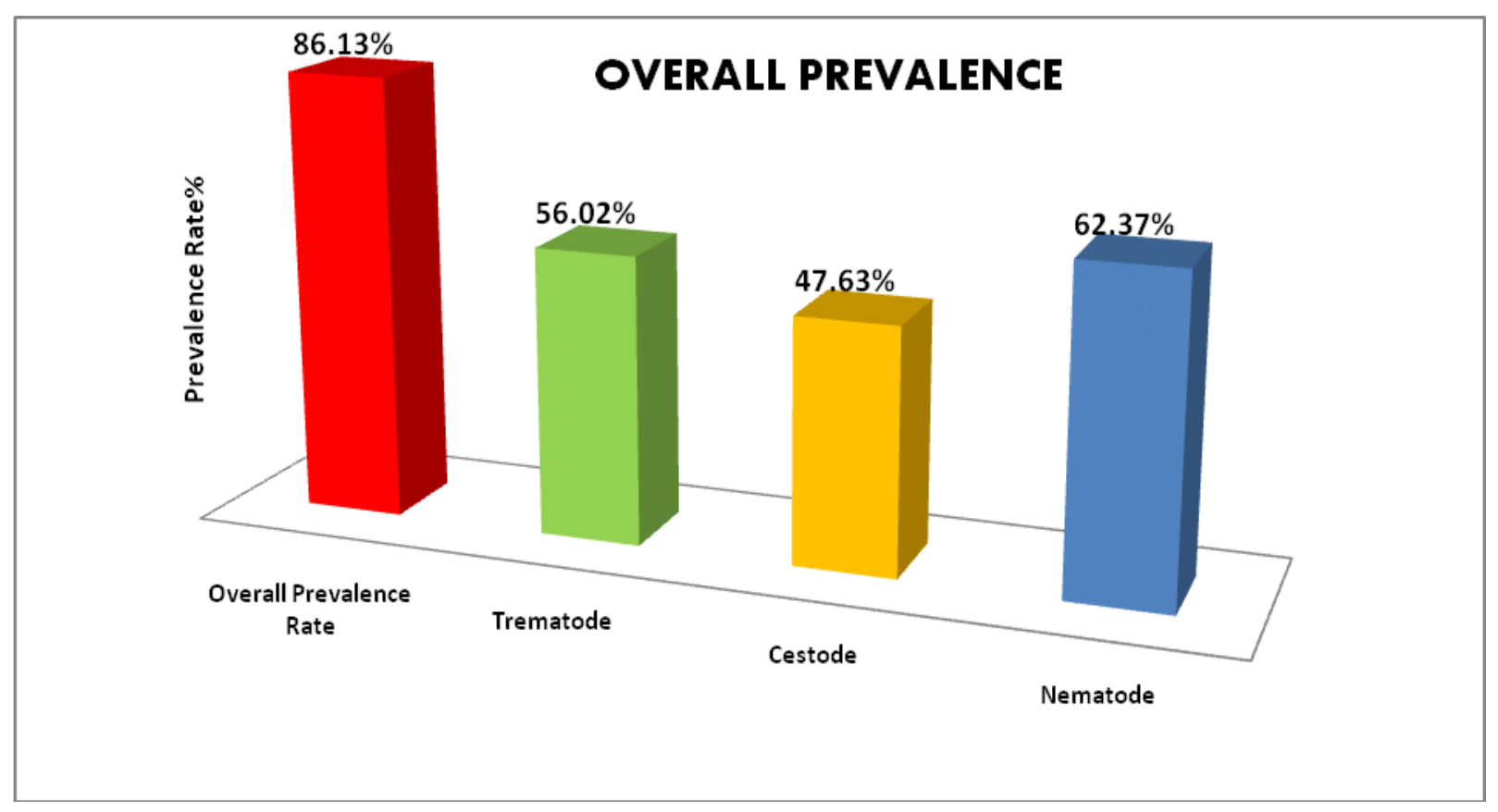


Fig.2 Seasonal Prevalence (\%) of GI helminths in goats in and around Ranchi

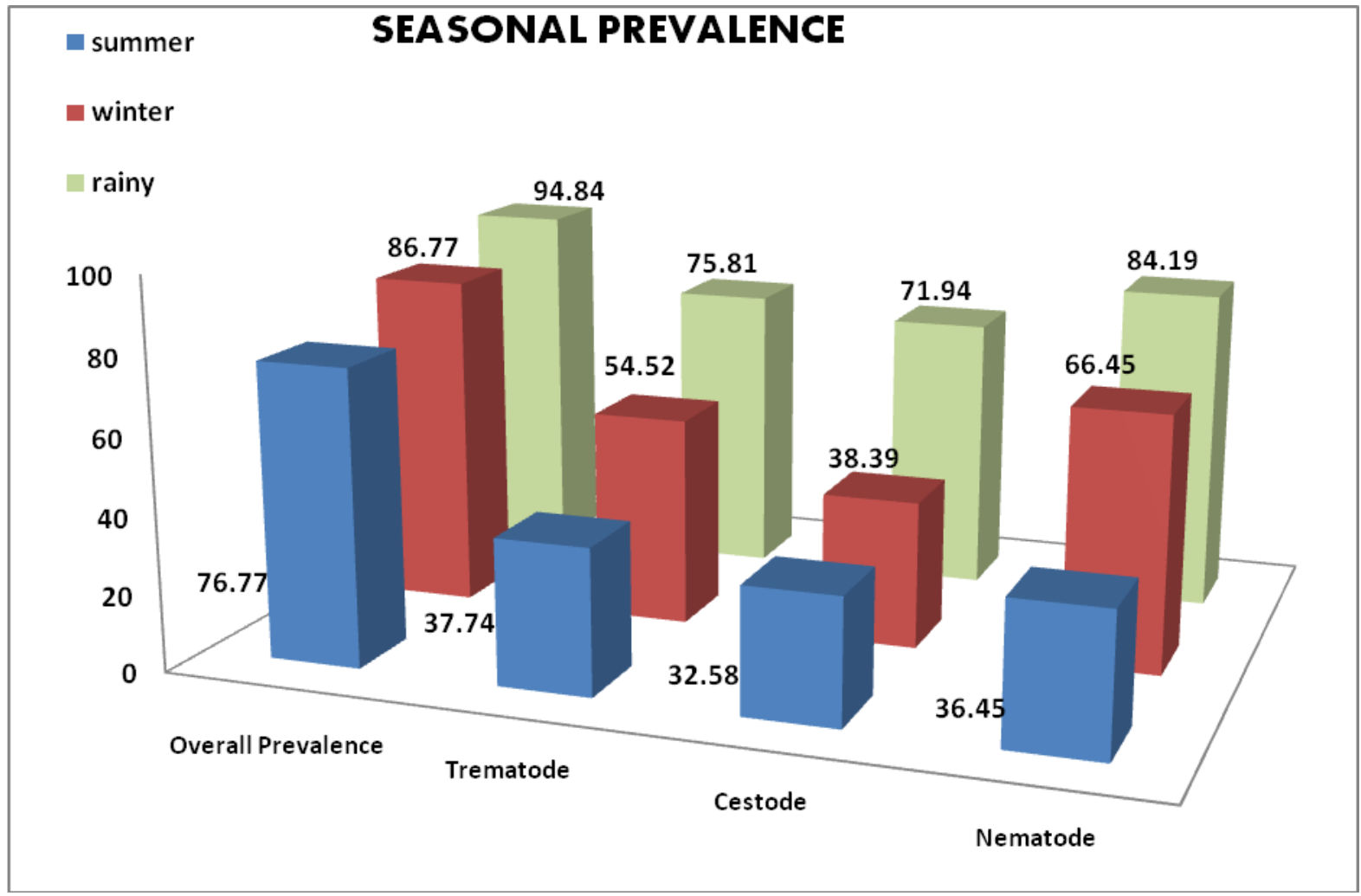

Fig.3 Age wise prevalence (\%) of GI helminths in goats in and around Ranchi

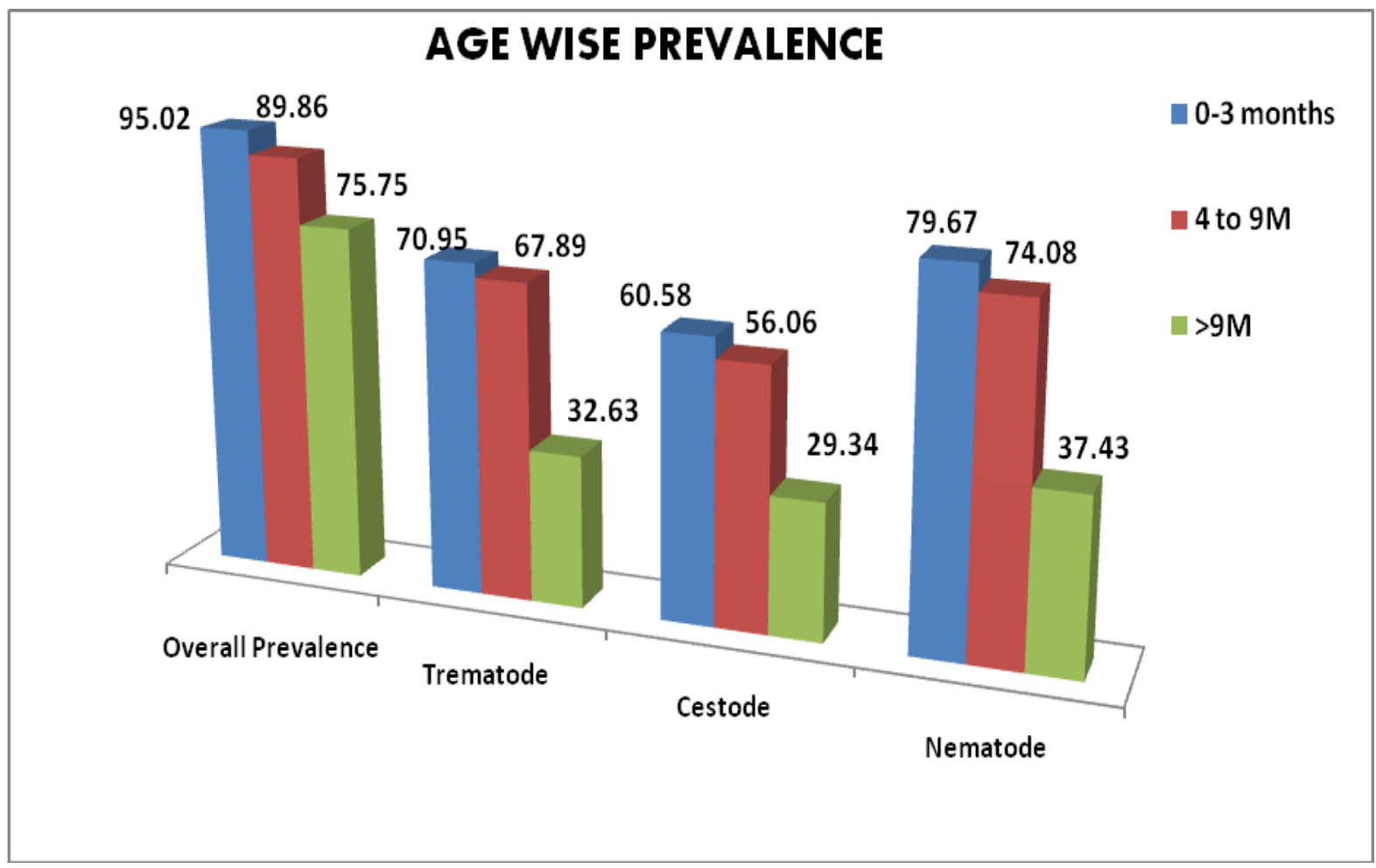


Fig.4 Sex wise prevalence (\%) of GI helminths in goats in and around Ranchi

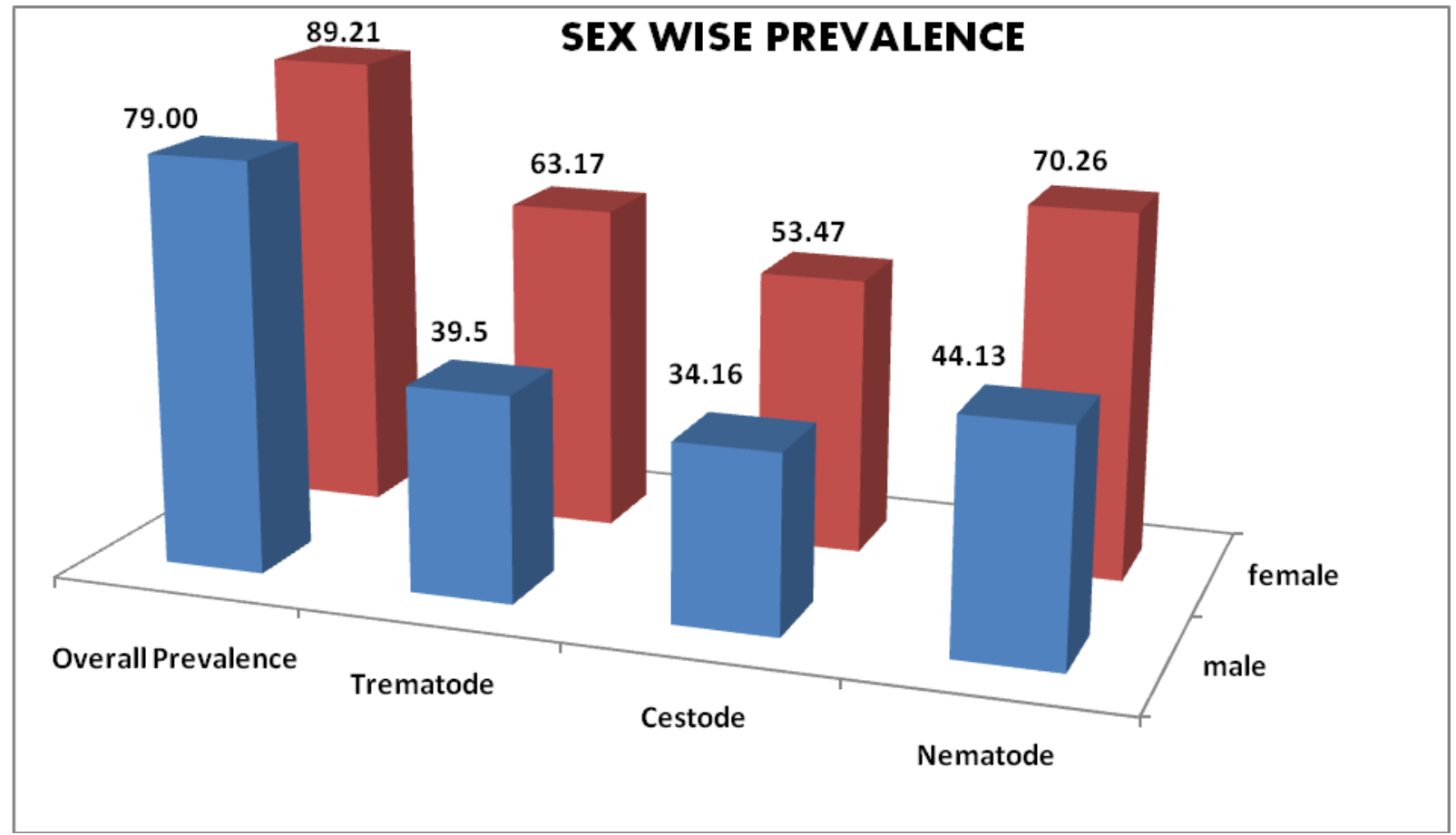

Rainy season was recorded to have highest overall prevalence of $94.84 \%$ followed by $86.77 \%$ in winter and the lowest being recorded at $76.77 \%$ in the summer months $(\mathrm{P}<0.01) \quad$ (Table 1and Figure 2). The relationship between season and infection was found to be highly significant $(\mathrm{P}<0.01)$. Among all the GI helminths viz. trematodes, cestodes and nematodes, it was observed that higher prevalence was being recorded in Rainy season at $75.81 \%, 71.94 \%$, and $84.19 \%$ respectively. In winter nematodes were recorded to have highest prevalence $(66.45 \%)$ followed by trematodes $(54.52 \%)$ and cestodes (38.39\%). Summer was found to be with least prevalence rate, viz. trematodes, cestodes and nematodes at $37.74 \%, 32.58 \%$ and $36.45 \%$, respectively (Table 1and Figure 2). Similar findings were also recorded by Gaherwal et al., (2016), Sanalkumar et al., (2017) and Jena et al., (2108). In rainy season, the higher prevalence of gastrointestinal helminths can be accredited to a number of favorable climatic conditions such as high relative humidity, rainfall, soil salinity, ambient temperature. These climatic conditions help in adequate growth and development of the infective larval stages in rainy season. It's also well documented that larval availability and pasture contamination is directly related to helminth infection (Soulsby, 1966 and Sanyal, 1998). Comparatively lower infection rate in winter can be a result of arrested development of larval stages due to cold stimuli and stall feeding practices in the winters as reported by Hutchinson and coworkers in 1972.

Age wise prevalence showed strong statistical evidence $(\mathrm{P}<0.01)$ of relationship between different age groups and gastrointestinal helminths infection. Younger animals (0 to 3 months at $95.02 \%$ ) showed higher infection rate in comparison to adults' viz. 4 to 9 months at $89.86 \%$ and more than 9 months at $75.75 \%$ (Table 1and Figure 3). Molla and Bandyopadhyay (2016), Poddar et al., (2017) and Jena et al., (2018) found similarly higher 
and lower rate of prevalence among younger age groups and adult animals, respectively. 03 months age group was also recorded to have highest prevalence $(79.67 \%)$ of nematode infection. The lowest infection was recorded in $>9$ month age group of cestodes $(29.34 \%)$ (Table 1and Figure 3). The reason for kids (03 month age group) harboring significantly higher infection may be since previous infections and age of the animals provide protection against recurrent infections as a result younger animals most commonly suffer from acute infections, as opined by Soulsby in 1966.

Females $(89.21 \%)$ were recorded with higher prevalence rate in comparison to males $(79 \%)$ and the relationship was highly significant $(\mathrm{P}<0.01)$ (Table 1and Figure 4). Similarly higher prevalence among trematodes, cestodes and nematodes was recorded in females' viz. $63.17 \%, 53.47 \%$ and $70.26 \%$ whereas lower prevalence was recorded in males viz. 39.50\%, 34.16\% and $44.13 \%$, respectively (Table 1and Figure 4). This was evident among all the GI helminths as shown in Table 1. Similar findings were also reported by Islam et al., at Mymensingh, Bangladesh in 2017, Dabasa et al., at Bale zone of south eastern Ethiopia in 2017, Rizwan et al., (2017) at Sialkot district of Punjab, Pakistan and recently by Jena and coworkers in 2018 in and around Ranchi. Other workers like, Asif et al., (2007) and Raza et al., (2014) reported inconsistent results in prevalence of gastrointestinal parasite infection. The females might be more susceptible gastrointestinal infections due to high stress and low immunity status in female animals during lactational period, post parturient period and also when the animal is pregnant (Islam et al., 2017; Dabasa et al., 2017; Jena et al., 2018).

This present study observed very high prevalence of gastrointestinal helminths infection in goats of Ranchi and its surrounding locality. This epidemiological study can be used in formulation of a strategic gastrointestinal helminth management.

\section{Acknowledgment}

The authors are thankful to the Dean, Ranchi College of Veterinary Science and Animal Husbandry, Kanke, Ranchi for providing all the facilities to undertake this research work.

\section{References}

Ahmed, J., Duguma, A., Regassa, D., Belina, D. and Jilo, R. 2017. Gastrointestinal nematode parasites of small ruminants and anthelmintics efficacy test in sheep of Haramaya district, Eastern Ethiopia. Animal and Veterinary Sciences. 5(3):39-44.

Asif, R.M., Iqbal, Z., Jabbar, A. and Yaseen, M. 2007. Point prevalence of gastrointestinal helminthiasis in ruminants in southern Punjab, Pakistan. Journal of Helminthology. 81:323-328.

Bandyopadhyay, S., Devi, P., Bera, A., Bandyopadhyay, S. and Bhattacharya, D. 2010. Prevalence of Gastrointestinal Parasite in Goats in Shillong, Meghalaya, India. Webmed Central Parasitolog. 1(9):WMC00777.

Dabasa, G., Shanko, T., Zewdei, W., Jilo, K., Gurmesa, G. and Abdela, N. 2017. Prevalence of small ruminant gastrointestinal parasites infections and associated risk factors in selected districts of Bale zone, south eastern Ethiopia. Journal of Parasitology and Vector Biology. 9:81-98.

DAHD and F. 2012. 19 Livestock Census2012 All India Report. Available from:http://www.dahd.nic.in/documents /statistics/livestockcensus.

Gaherwal, S., Prakash, M.M. and Dudwe, J. 2016. Prevalence and incidence of 
nematodes in goats at five different villages of Barwani district, Mathya Pradesh. International Journal of Advanced Research. 4(3):1126-1137.

Gupta, A., Dixit, A.K., Dixit, P. and Mahajan, C. 2013. Prevalence of gastrointestinal parasites in small ruminants in and around Jabalpur, India. Journal of Veterinary Parasitology. 27(1):59-60.

Hutchinson, G.W., Lee, E.H. and Fernando, M.A. 1972. Effects on variation in temperature on infective larvae and their relationship to inhibited development of Obeliscoides cuniculiin rabbit. Parasitology. 65: 333-342.

Islam, M.S., Hossain, M.S., Dey, A.R., Alim, M.A., Akter, S. and Alam, M.Z. 2017. Epidemiology of gastrointestinal parasites of small ruminants in Mymensingh, Bangladesh. Journal of Advanced Veterinary and Animal Research. 4(4):356-362.

Jena, A., Deb, A.R., Kumari, L., Biswal, S.S. and Joshi, S.K. 2018. Pattern of Occurrence of Gastrointestinal Helminthiasis in Chottanagpuri sheep in and around Ranchi, Jharkhand. Journal of Entomology and Zoology Studies. 6(1): 175-178

Jithendran, K.P. 2000. Helminth Parasites - A Constraint in Animal Health Management in Himachal Pradesh. ENVIS Bulletin - Himalayan Ecology \& Development. 8(2): 7-20.

Location of Ranchi, Jharkhand. 2018. https://www.weatherforecast.com/locations/Ranchi.

Molla, S.H. and Bandyopadhyay, P.K. 2016. Prevalence of gastro-intestinal parasites in economically important Bonpala sheep in India. IOSR Journal of Agriculture and Veterinary Science. 9(1):87-93.

Poddar, P.R., Begum, N., Alim, M.A., Dey, A.R., Hossain, M.S. and Labony, S.S. 2017. Prevalence of gastrointestinal helminths of sheep in Sherpur, Bangladesh. Journal of Advanced Veterinary and Animal Research. 4(3):274-280.

Raza, M.A., Younas, M. and Schlecht, E. 2014. Prevalence of gastrointestinal helminths in pastoral sheep and goat flocks in the Cholistan desert of Pakistan. The Journal of Animal \& Plant Sciences. 24:127-134.

Rizwan, H.M., Iqbal, Z., Sajid, M.S. and Saqib, M. 2017. Point prevalence of gastrointestinal parasites of domestic sheep (Ovis aries) in district Sialkot, Punjab, Pakistan. Journal of Animal and Plant Sciences. 27(3):803808.

Sanalkumar, K., Purayil, A.A., Rajan, P., Kalarikkal, D.C., Narayanan, P.M. and Ravindran, R. 2017. Pattern of occurrence of gastrointestinal strongylosis in an organized caprine farm of Wayanad district, Kerala, South India. International Journal of Current Microbiology and Applied Sciences. 6(2):1038-1042.

Sanyal, P.K. 1998. Integrated gastrointestinal parasite management in dairy animals in Gujarat by self-medication. Journal of Veterinary Parasitology. 12:17-20.

Shan, H.L. and Chaudhry, R.K. 1995. Parasitism in dairy animals in India: Present status and its impact. In Proceedings of the workshop on control strategy against gastrointestinal parasites in dairy animals in India using medicated urea molasses blocks. NDDB, Anand, India. 1-5.

Sloss, M.W., Kemp, R.L. and Zajac, A.M. 1994. Veterinary Clinical Parasitolgy. $6^{\text {th }}$ Edn. International Book Distributing Co., Lucknow, India. 417-419.

Sohail, M., Nauman-ul-Islam, M., Shah, S.S.A., Shah, I.A., Raziq, A. and Ilyas, M. 2107. Incidence of gastrointestinal parasites in beetal goats at district 
Peshawar, Pakistan. Advances in Animal and Veterinary Sciences. 5(5):205-207.

Soulsby, E.J.L. 1966. Biology of Parasites. Academic Press, New York and London. pp-185-196.

Velusamy, R., Rani, N., Ponnudurai, G. and Anbarasi, P. 2015. Prevalence of intestinal and haemoprotozoan parasites of small ruminants in Tamil Nadu, India. Veterinary World. 8(10):1205-
1209.

Yeasmin, T., Khanum, H. and Zaman, R.F. 2015. Seasonal prevalence of arthropoda and helminth parasites in sheep (Ovis aries). Bangladesh Journal of Zoology. 42:45-55.

Zajac, A.M. and Conboy, G.A. 2011.Veterinary Clinical Parasitology. $8^{\text {th }}$ Ed. Wiley-Blackwell Publication, Chichester, West Sussex, UK.

\section{How to cite this article:}

Anurag Jena, Asit Ranjan Deb, Lalita Kumari, Subhranshu Sekhar Biswal and Joshi, S.K. 2018. Prevalence of Gastrointestinal Helminthes among Goats in and around Ranchi, Jharkhand, India. Int.J.Curr.Microbiol.App.Sci. 7(01): 3506-3513.

doi: https://doi.org/10.20546/ijcmas.2018.701.412 